\title{
Death of an infant in hyperthermia after vaccination
}

\author{
K. Apostolovi1, T. H. FLEWETt, AND THE LATE K. S. THOMPSON \\ From the Regional Virus Laboratory and Department of Pathology, Little \\ Bromwich Hospital, Birmingham
}

SYNOPSIS Death following hyperpyrexia and coma of rapid onset nine days after vaccination of an infant is reported. Death appeared to be due to overwhelming vaccinial infection withoul encephalitis. Large amounts of virus was present in lung, spleen, bone marrow, and the vaccinatiof site.

Three sometimes fatal complications of vaccinia are well known: post-vaccinial encephalitis, generalized vaccinia, and progressive vaccinia. This report describes a fourth variety.

\section{CLINICAL HISTORY}

A baby girl, 3 months old, was vaccinated on the upper arm by a general practitioner using the 'multiple pressure' method. The baby was seen by a health visitor on the seventh day after vaccination and appeared well; the vaccination showed a normal 'take'. The parents reported that on the evening of the eighth day she appeared well; at 6.30 a.m. the following morning she 'looked all right'; at 8.30 a.m. the child could be roused, but was very sleepy; at 9 a.m. she could not be wakened, and when the doctor arrived at 9.10 a.m. the child was dead. The body felt extremely hot to the touch and was steaming. The rectal temperature was at least $108^{\circ} \mathrm{F} .\left(42 \cdot 2^{\circ} \mathrm{C}\right.$.), the highest figure on the thermometer scale.

\section{NECROPSY FINDINGS}

Externally the body was that of a well-nourished, wellcared for female infant, with the blister of a recent vaccination on the left upper arm. The tongue was clenched tightly between toothless gums. Both hands were clenched and the arms rigidly flexed. Although death was stated to have occurred seven hours previously, the temperature of the body was $97^{\circ} \mathrm{F}$. when it was opened in the unheated post-mortem room in late November.

Within the body, there were very extensive asphyxial haemorrhages in the pericardium, thymus, and pleura. The heart and lungs were otherwise normal except that the airways were filled with a very fine white froth. There was congestion and cloudy swelling of liver and kidneys, and a congested spleen. There was no evidence of any

Received for publication 22 July 1960.

'Present address: Institute of Hygiene, Skopje, Yugoslavia. sepsis beneath the vaccination wound, and no evideat abnormality in the alimentary tract.

The brain showed extreme pink suffusion of the grey and white matter.

\section{LABORATORY INVESTIGATIONS}

Necropsy specimens were taken from the following orga for histology and for virological examination: Cerebrigl cortex, kidney, spleen, a rib (for bone marrow), lung, heart, and the skin bearing the vaccination lesion. FQr histology the tissue was fixed in formal saline and $f \overrightarrow{\mathrm{g}} \mathrm{r}$ virology was stored at $-30^{\circ} \mathrm{C}$. until eggs and tissme cultures were ready for inoculation. The skin lesion was all taken for virus titration and was not examined histologically.

Suspensions of tissue, $10-20 \%(w / v)$, were made $\overline{b y}$ grinding with sterile pyrex powder in a mortar and weipe titrated in eggs using eight eggs per 10-fold dilution by the method of Overman and Tamm (1956); as a checg, infectivity titres in terms of $T_{C D}$ for ERK 1 ce\#ts (Westwood, Macpherson, and Titmuss, 1957) were also determined, using four tubes per 10-fold dilution. The infectivity end-point was determined as shown af seven days' incubation, though it is possible that with further incubation the titre might have appeared highe The titres are shown in Table I. No virus was isolated from brain or kidneys either in eggs or tissue cultues. There was no evidence of virus other than vaccinia any specimen,

\section{TABLE I}

TITRES OF TISSUES EXAMINED

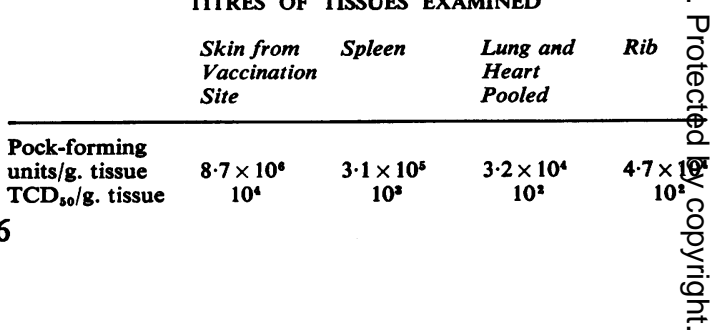


No sample of blood was taken during the course of the illness and neutralizing antibodies were not looked for.

\section{HISTOLOGY}

Unfortunately no sections of the lung were available. The only changes visible in the other organs were acute cloudy swelling of liver, kidney, and brain; the blood vessels in the brain appeared very congested. No inclusion bodies were found. (The skin lesion was not examined.) There was no evidence of perivascular fragmentation or loss of myelin or of acute inflammatory change in the brain.

\section{DISCUSSION}

The recognized complications of vaccination are post-vaccinial encephalitis, generalized vaccinia (usually associated with eczema), and progressive vaccinia (a rare disease, possibly associated with agammaglobulinaemia).

The course of events in this case differs from any of these. The interval between vaccination and death was shorter than that described in well-authenticated reports of post-vaccinial encephalitis. It seems most probable that there was an acute overwhelming vaccinial infection with associated toxaemia leading to hyperpyrexia and death. This, however, does not entirely explain the asphyxia, which we can only account for by postulating spasm of the bronchioles, perhaps as an allergic reaction to large quantities of vaccinial antigen. The reaction appears to be an individual one; another child inoculated on the same day by the same practitioner with the same batch of vaccine behaved normally. As far as we are aware, no report of a precisely similar fatality due to vaccination has been published. It may be that they have been diagnosed as 'vaccinial encephalitis'. Such a provisional diagnosis was made in this case until it became clear, on histological examination of the brain, that there was no encephalitis. Dr. Marmion has, however, told us of a somewhat similar death with hyperpyrexia $\left(106^{\circ} \mathrm{F}\right.$. $\left(41 \cdot 1^{\circ} \mathrm{C}\right.$.) recorded) in an infant nine days after vaccination, which he investigated serologically. In this case, though intensive attempts were made to isolate vaccinia, enteroviruses, and influenza virus, all cultures were negative except those from the vaccination site from which vaccinia virus was isolated. At necropsy, there was no evidence of encephalitis but some evidence of pneumonia with a mononuclear cell exudate.

The lesions on the chorioallantoic membrane produced by the virus isolated from this patient were indistinguishable from those produced by vaccine lymph. They did not show any unusually marked necrosis in the centre of the pocks, as has been described for 'neurovaccinia'.

The investigation of this case has been by no means as complete as we could have wished. We are reporting it in the hope that pathologists will be on the look-out for such cases and will undertake a more detailed virological and histological examination of any that may occur.

Our thanks are due to Dr. B. P. Marmion, Dr. Denis Harriman and Dr. Kenneth Froome for information about patients investigated by them, and Professor A. W. Downie, F.R.S. for his comments.

\section{REFERENCES}

Overman, J. R., and Tamm, I. (1956). J. Immunol., 76, 228. Westwood, J. C. N., Macpherson, I. A., and Titmuss, D. H. J. (1957). Brit. J. exp. Path., 38, 138. 